\title{
FACTORS INFLUENCING TRAVEL BEHAVIOURAL INTENTIONS OF INTERNATIONAL TOURISTS TO SAUDI ARABIA
}

\author{
Nadin Almadani' ${ }^{1}$, Thu-Huong Nguyen ${ }^{2} \&$ Scott Bingley ${ }^{3}$ \\ ${ }^{1,2,3}$ College of Business Victoria University \\ (Nadin.almadani@live.vu.edu.au; Thu-Huong.Nguyen@vu.edu.au; Scott.bingley@vu.edu.au)
}

\begin{abstract}
This research aims to identify the factors affecting the behaviour of international tourists based on online reviews. To further understand tourist perceptions and opinions from online posts reviews Netnography approach has been implemented. A few studies have used Netnography to investigate online reviews of hotels and restaurants, but there has been limited examinations of online reviews of tourist attractions. To date, no studies have been done on this concerning Saudi Arabia. The OutWit Hub software was used to extract TripAdvisor reviews and content automatically. The data collection focused on attractions (Things To Do) located in Jeddah and Riyadh, the most populated cities in Saudi Arabia with a wide range of attractions and activities, including sights and landmarks, nature parks, and museums. The following approaches were utilised for netnographic analysis: first form the studied culture or group; collect data; analysis and interpretation: report on study findings and comprehend the theoretical consequences. The most significant findings were that the data supported correlations between visitors' behavioural intentions, travel motivations and experience quality. This research provides evidence that travel motivations and experience quality affect the development of tourist behavioural intentions. This research offers policymakers, destination planners and industry professionals a proper and thorough analysis of tourists' behaviour and needs.
\end{abstract}

KEYWORDS: online reviews, Netnography, tourists experience, travel behaviour, travel motivation and experience quality

\section{PURPOSE AND BACKGROUND}

This research aims to identify the factors affecting international tourists' behavioural intentions based on tourist online reviews. To further understand tourists' perceptions and opinions from online post reviews, a Netnography approach has been implemented. A few studies have employed Netnography to investigate online reviews of hotels and restaurants, but to date there has been limited examination of online reviews about tourist attractions. No studies have yet been done using this approach with reference to Saudi Arabia.

\section{METHODOLOGY}

The OutWit Hub software was used to automatically extract the content of TripAdvisor reviews. The data collection focused on attractions (things to do) located in Jeddah and Riyadh, which are the most populated cities in Saudi Arabia with a wide range of attractions and activities including sights and landmarks, nature parks and museums. The following Netnographic data collection including analysis, reporting and interpretation of results, was implemented:

1. gaining "entrée" into or formulating the culture or group one wants to investigate;

2. data collection; 
3. analysis and interpretation;

4. reporting the research findings; and

5. understanding the theoretical implications.

\section{FINDINGS}

The most significant findings were that the data supported correlations between visitors' travel motivations and quality of experience, which influenced their behavioural intentions. After analysing many reviews, Saudi Arabia's culture and scenery have emerged as the main factors attracting vacationers to the country. Furthermore, the study found that people were driven by the desire to interact with others, learn new knowledge and/or escape and relax. The study also found that joyful travel experiences included experiencing places hedonically or simply as something new.

\section{CONCLUSION}

Undertaking a travel behaviour assessment provides an opportunity to better understand the various decisions and behaviours that unfold throughout a travel experience. Travel motivations and experience quality are important determinants of revisit and recommendation intentions.

\section{CONTRIBUTION/PRACTICAL IMPLICATIONS}

This research provides evidence that travel motivations and quality of experience affect the progress of tourist behavioural intentions. The research also offers tourism policy-makers, destination planners and industry professionals a proper and thorough analysis of tourists' behaviours and needs.

\section{REFERENCES}

Chen, C.-F., \& Chen, F.-S. (2010). Experience quality, perceived value, satisfaction and behavioral intentions for heritage tourists. Tourism Management, 31(1), 29-35.

Shaw, A. (2020). Netnography and a summative content analysis approach to market research. Journal of Emerging Trends in Marketing and Management, 1(1), 12-22.

Woodside, A. G., \& Dubelaar, C. (2002). A general theory of tourism consumption systems: A conceptual framework and an empirical exploration. Journal of Travel Research, 41(2), 120-132. 